\title{
PENGEMBANGAN MODEL MITIGASI RISIKO KETERLAMBATAN PROYEK BERBASIS FAILURE MODE AND EFFECT ANAL YSIS: STUDI KASUS DI PT X
}

\author{
Andrey Ferdian Rumpuin ${ }^{1}$, Didik Wahjudi², dan Doddy Prayogo ${ }^{3}$ \\ ${ }^{1}$ Mahasiswa Program Studi Magister Teknik Sipil, Universitas Kristen Petra, Surabaya \\ 2,3 Dosen Program Studi Magister Teknik Sipil, Universitas Kristen Petra, Surabaya \\ ${ }_{1}^{1}$ b21180007@john.petra.ac.id, ${ }^{2}$ dwahjudi@petra.ac.id, ${ }^{3}$ prayogo@peter.petra.ac.id
}

\begin{abstract}
ABSTRAK: Banyak penelitian dilakukan untuk mempelajari faktor keterlambatan proyek konstruksi jalan di Kota Ambon. Penelitian ini bertujuan meminimalkan risiko dan dampak keterlambatan yang dialami PT X. Penelitian menggunakan metode failure mode and effect analysis (FMEA) karena dapat memprioritaskan risiko proyek menggunakan item pekerjaannya. Prioritas dipilih dari risk priority number (RPN) yang di atas 125. Pengambilan data dilakukan dua kali wawancara dan teknik 5 Whys digunakan mencari akar permasalahan. Hasil wawancara merupakan faktor risiko yang menyebabkan keterlambatan, nilai RPN diambil dari pedoman tabel yang ditetapkan, menganalisis risiko, memberikan solusi dan memastikan nilai RPN lebih kecil dari 125. Hasil penelitian ditemukan kemiripan faktor risiko yang menyebabkan keterlambatan antara proyek 1 dan proyek 2, dengan proses pengerjaan di tahun yang bebeda. Faktor-faktor risiko tersebut terjadi karena penerapan sistem di perusahaan yang kurang diperhatikan. Implentasi metode FMEA untuk proyek konstruksi dapat digunakan meskipun item pekerjaannya banyak.
\end{abstract}

Kata kunci: FMEA, risiko kegagalan, keterlambatan proyek

\begin{abstract}
Lots of research have been conducted to study the unpunctuality of road construction projects in Ambon. This research intended to minimize the risk and impact of the delay by PT $X$ using the Failure Mode and Effect Analysis (FMEA) method to prioritize risk. The risk priority number (RPN) values above 125 indicate the prioritized work items. Data collection was by two interviews and using the 5 Whys technique to obtain the core issue. The resulted finding risk factors causing the delay, RPN value taken from specified table guidelines, analyzing risks, giving solution, and ensure the RPN value lesser than 125. The research found similarity of the risk factor in project 1 and project 2, with a different year of the working process. These risk factors happened due to the neglected system implementation in the company. Implementation of the FMEA method for construction projects can be used in numerous work items.
\end{abstract}

Keywords: FMEA, failure risk, project delay 


\section{PENDAhULUAN}

Bisnis di bidang konstruksi dihadapkan degan berbagai macam risiko kegagalan yang dapat terjadi. Di satu sisi, keberhasilan dalam melaksanakan suatu proyek konstruksi merupakan hal yang perlu diperhatikan agar terhindar dari kerugian dari segi tenaga, waktu dan biaya yang tidak diinginkan oleh pihak manapun. Oleh sebab itu pelaksanaan suatu pekerjaan konstruksi memerlukan adanya penentuan prioritas dari risiko-risiko tersebut agar dampak negatifnya dapat terminimalisir. Menurut Lambobang (2011), risiko kegagalan pada proyek konstruksi dapat diminimalisir dengan pendekatan melalui manajemen risiko yang meliputi proses perencanaan manjemen risiko, identifikasi risiko, analisa risiko, perencanaan respon risiko, implementasi respon risiko, dan memonitior risiko (Guide, 2017). Dengan melakukan manajemen risiko diharapkan dapat meminimalisir probabilitas dan/atau dampak risiko serta mengoptimalkan peluang keberhasilan proyek.

Salah satu dari beberapa macam manajemen risiko yang sistematis adalah metode failure mode and effect analysis (FMEA) (Bahrami, Bazzaz, \& Sajjadi, 2012). Menurut Ebrahemzadih, Halvani, Shahmoradi, and Giahi (2014), FMEA disebut sebagai metode yang sistematis karena beberapa hal berikut: 1) dapat mengidentifikasi dan memprioritaskan mode kegagalan potensial dalam suatu sistem atau proses, 2) dapat menetapkan dan menjalankan langkah-langkah untuk menghilangkan atau mengurangi timbulnya risiko kegagalan potensial, 3) dapat mencatat hasil analisis untuk memberikan referensi yang komprehensif untuk memecahkan masalah di masa depan, dan 4) dapat menghitung efek kegagalan pada langkah di atas.

Dalam kesempatan ini, peneliti ingin menerapkan FMEA pada proyek yang dikerjakan oleh PT. X, sebuah perusahaan yang bergerak di bidang konstruksi jalan raya di Kota Ambon. PT. X sudah berdiri lebih dari lima tahun dan sering mengalami keterlambatan penyelesaian pekerjaan. Keterlambatan dari PT. X bahkan sampai dengan lima bulan dari perjanjian kontrak proyek. Hal ini menunjukkan bahwa PT. X kurang mampu mengidentifikasi risiko-risiko yang ada sehingga peneliti merasa diperlukannya metode yang sistematis untuk mencari faktor penyebab keterlambatan serta memberikan solusi yang tepat agar di kemudian hari PT. $X$ dapat dengan efektif menyelesaikan proyek dengan tepat waktu.

\section{LANDASAN TEORI}

\subsection{Risk Management}

Risk management merupakan proses mengidentifikasi, memantau dan mengelola risiko potentisal untuk meminimalkan dampak negatif yang ditimbulkan terhadap suatu organisasi. Risiko itu sendiri merupakan suatu kemungkinan terjadinya sesuatu yang buruk atau hilangnya sesuatu yang bernilai. Dalam dunia bisnis, risiko merupakan hal yang harus dipertimbangkan secara mendalam agar tujuan perusahaan dapat tercapai. Dengan begitu perlu dilakukannya manajemen risiko terlebih dahulu agar risiko dapat teratasi. Tahapan-tahapan untuk melakukan manajamen risiko menurut Guide (2017) adalah sebagai berikut:

1. Merencanakan manajemen risiko (Plan risk managament);

2. Mengidentifikasi risiko (Identiry the risk);

3. Mengalanisis risiko (Analysis risk);

4. Merencanakan respon risiko (Plan risk responeses);

5. Mengimplementasi respon risiko (Implement risk responses); 


\section{Melacak risiko (Monitor risk).}

\subsection{Metode Identifikasi Risiko}

Secara umum metode identifikasi risiko dapat dikelompokkan menjadi 2 (dua), yaitu:

1. Metode Perbandingan, yakni dengan membandingkan rancangan terhadap suatu standard atau desain, seperti daftar periksa (checklist). Cara pemeriksaan juga mencakup Audit K3 (Safety Audit); 2. Metode Fundamental, yakni merupakan cara yang tersusun untuk memotivasi orang yang menerapkan pengetahuan dan pengalaman mereka dengan tujuan mengidentifikasi bahaya (Wachyudi, 2010). Metode ini terdiri atas beberapa macam cara, yakni:

a. Preliminary Hazard Analysis (PHA);

b. What-If;

c. Fault Tree Analysis (FTA);

d. Failure Mode and Effect Analysis (FMEA).

\subsection{Identifikasi Failure Mode}

FMEA pada umumnya digunakan untuk mengidentifikasi kesalahan pada proses kerja yang secara garis besar terdiri atas dua bagian, yakni failure modes dan effects analysis. Failure modes merupakan suatu proses segala bentuk kemungkinan yang akan mengalami kegagalan atau kesalahan yang ditemukan, sementara effects analysis adalah untuk menganalisis konsekuensi yang akan atau terjadi dari setiap kegagalan yang ada. Singkatnya, pengamatan yang dilakukan adalah dengan melihat setiap sub-item proses pekerjaan agar dapat dianalisa. Metode FMEA seringkali digunakan sebab metode ini dapat mengidentifikasi risiko dan memprioritaskan penyebab yang berbeda berdasarkan tingkat kepentingannya (Tafazzoli, 2017) Selain itu FMEA juga merupakan metode yang sistematis, sehingga dapat diketahui akar permasalahan yang sebenarnya terjadi (Bahrami, Bazzaz, \& Sajjadi, 2012).

Metode FMEA diciptakan dengan tujuan sebagai berikut:

a. Meningkatkan kualitas kerja sehingga dapat fokus dalam item pekerjaan terutama prioritas aktivitas tersebut.

b. Mengurangi waktu yang terbuang karena kesalahan metode yang digunakan, kendala yang ada dalam aktivitas tersebut.

c. Menghemat biaya yang tidak diperlukan karena kesalahan kerja.

d. Mengurangi risiko kemungkinan yang akan terjadi selama proses kerja.

e. Memperkirakan solusi yang akan terjadi sehingga ada antisipasi yang dapat dilakukan jika permasalahan tersebut terjadi.

Dalam menggunakan tools FMEA, terdapat beberapa tahapan penting yang perlu diperhatikan guna memperoleh hasil yang benar. Tahapan-tahapan tersebut ialah sebagai berikut:

1. Membuat rundown pekerjaan dari awal hingga proses terakhir.

2. Membuat analisis potensi pekerjaan yang dapat menghambat proses pekerjaan/kesalahan yang sering terjadi.

3. Membuat daftar keterangan akibat dari kegagalan tersebut.

4. Memberikan penilaian menggunakan angka skala 1-10, dimana angka 1 merupakan skala tidak parah / tidak sering / dapat dideteksi, hingga angka 10 merupakan skala sangat parah / sering sekali / tidak dapat dideteksi.

5. Menggunakan rumus risk priority number $(\mathrm{RPN})=\mathrm{S}$ (severity) $\times \mathrm{O}$ (occurance) $\times \mathrm{D}$ (detection), kemudian melakukan pengisian skala pada setiap komponen di atas. 
6. Melakukan perhitungan perkalian dan penyeleksian dari hasil $R P N=S \times O \times D$, perkalian yang memiliki jumlah tertinggilah yang merupakan item pekerjaan yang harus lebih diperhatikan.

7. Melakukan pengambilan solusi dimana dari item pekerjaan tersebut benar-benar terjadi, langkah-langkah apa saja yang harus diperhatikan.

8. Melakukan kontrol dan memperhatikan secara lebih proses yang sedang berlangsung.

9. Melakukan survey ulang untuk melihat perubahan atau perkembangan perubahan setelah menggunakan FMEA, jika tidak ada perubahan maka diperlukan tinjauan ulang untuk menentukan faktor permasalahan tersebut.

Pelaksanaan metode FMEA tidak terlepas dari adanya tabel severity, occurence, dan detection (SOD). Tabel tersebut merupakan tabel panduan untuk menganalisa risiko sesuai dengan keterangan yang ada pada tabel yang telah dipilih sesuai dengan kebutuhan yang diperlukan. Hasil SOD akan diperoleh dengan menentukan setiap penilaian pada kolomnya.

\subsection{FMEA in Construction}

Pada umumnya, metode FMEA diterapkan untuk mengidentifikasi risiko pada industri namun hal tersebut tidak menutup kemungkinan bagi penerapan metode FMEA di bidang konstruksi. Hal tersebut sejalan dengan pendapat dari Latief and Utami (2009) yang menyatakan bahwa FMEA sebagai salah satu tools yang ada dari six-sigma ini sangat membantu dalam dunia konstruksi terutama dalam kualitas di dalam proyek konstruksi. Dalam bidang konstruksi yang terutama adalah melakukan planning, metode, analisa risiko yang akan digunakan selama proyek berlangsung (Wehbe \& Hamzeh, 2013), oleh karena itu diperlukan FMEA dalam melakukan proyek konstruksi agar dapat menganalisa secara baik dan juga dengan tepat. Salah satu contoh penelitian penggunaan FMEA di bidang kontruksi dilakukan oleh Cheng \& Lu (2015), dimana terdapat suatu tabel SOD yang diaplikasikan dalam proyek konstruksi pemasangan saluran pipa untuk mengurangi keparahan risiko dalam konstruksi pemasangan saluran pipa.

\section{METODE PENELITIAN}

Penelitian yang dilakukan adalah dengan mendapatkan rundown activites / item pekerjaan sebagai pemecahan permasalahan yang ada pada proyek. Ketika sudah mendapatkan item pekerjaan maka akan dilakukan penambahan kolom SOD beserta keterngannya, dan melakukan wawancara ke narasumber. Pertanyaan-pertanyaan yang digunakan selama wawancara adalah dengan menggunakan pertanyaan 5 whys untuk mendapatkan akar permasalahannya. Keterangan wawancara yang sudah didapatkan akan dinilai menggunakan pedoman tabel yang sudah ditetapkan. Dalam penilaian diberikan oleh narasumber secara langsung dan akan didapatkan nilai RPN. Prioritas faktor risiko yang tertinggi maka akan diteliti lebih lanjut untuk mengurangi dampak risiko yang terjadi. Pengusulan solusi juga akan diberikan untuk mengurangi dampak risiko yang terjadi.

\section{HASIL PENELITIAN}

\subsection{Gambaran Umum Penelitian}

Penelitian ini dilakukan dengan proses secara bertahap dan berurutan agar dapat ditemukannya faktor risiko yang menyebabkan keterlambatan. Rangkaian proses selama penelitian yang dilakukan dapat dilihat pada keterangan sub-bab di bawah ini. 
Pada penelitian ini menggunakan metode FMEA yang diterapakan di PT X, dalam masalah keterlambatan proyek yang dikerjakan. Pada metode FMEA ini memiliki kelebihan yaitu dapat menganalisa dan memprioritaskan masalah yang terjadi. PT X merupakan kontraktor yang bergerak di bidang konstruksi jalan. Pengalaman yang dimiliki oleh PT $X$ dalam konstruksi jalan cukup banyak, karena PT X sudah berdiri lebih dari 5 tahun. Dalam mengerjakan proyek konstruksi jalan PT X sering mengalami keterlambatan. Keterlambatan yang dialami oleh PT X bisa mencapai hingga lima bulan dari perjanjian kontrak proyek.

Oleh karena itu, penulis ingin melakukan penelitian di PT X, agar dapat mengidentifikasi jenis risiko dan penyebabnya. Penelitian ini menggunakan metode FMEA yang sistematis dan dapat mencari faktor penyebab keterlambatan yang paling kritis. Dari hasil nilai RPN penulis dapat mengetahui prioritas faktor risiko dari item pekerjaan, dan melakukan pengusulan solusi agar proyek dapat diselesaikan dengan tepat waktu. Penelitian ini dilakukan untuk mengurangi risiko keterlambatan proyek konstruksi jalan. Sebagai berikut data proyek yang akan diteliti.

Data awal yang akan diberikan pada peneliti berdasarkan permasalahan yang ada di PT X oleh direkturnya sendiri. Permasalahan tersebut meliputi risiko kegagalan dalam bentuk keterlambatan proyek konstruksi jalan yang pernah dikerjakan oleh PT X. Untuk melakukan penelitian ini diperlukan item pekerjaan sebagai landasan penelitian. Dari item pekerjaan tersebut akan dilakukan beberapa langkah dari penentuan prioritas item pekerjaan paling kritis, pencarian akar permasalahan, dan hingga pengusulan solusi yang diberikan.

Pada penelitian ini ada dua proyek yang diberikan secara langsung oleh direktur PT X sebagai penelitian. Proyek yang diberikan berada dilokasi yang berbeda, namun proyek ini adalah proyek yang berkesinambungan. Kedua proyek yang diberikan tersebut memiliki jenis pekerjaan proyek yang sama yaitu, pekerjaan konstruksi lapisan penetrasi. Dimana pekerjaan lapisan penetrasi merupakan salah satu jenis konstruksi perkerasan jalan beraspal dengan sistem penyiraman lapisan penetrasi makadam. Dimana terdiri atas agregat pokok, agregat pengunci, agregat penutup dan aspal. Agregat pokok adalah batu $5 / 7$ yang berarti ukurannya kurang lebih $5 \mathrm{~cm} \times 7 \mathrm{~cm}$ (sebagai lapisan pondasi bawah / sub base), dan batu 2/3 (sebagai lapisan pondasi atas / base ). Agregat pengunci adalah batu $3 / 5$ (sebagai pengunci lapisan pondasi bawah), dan batu $1 / 2$ (sebagai pengunci lapisan pondasi atas). Agregat penutup adalah pasir halus sebagai lapisan permukaan, untuk menutup pori-pori permukaan. Pada setiap lapisan akan dilakukan pemadatan setiap struktur lapisan terlebih dahulu, kemudian akan dilakukan penyiraman aspal cair pada setiap lapisan pondasi dan permukaan untuk mengikat agregat.

Penentuan lokasi yang telah ditentukan membutuhkan perwakilan pekerja yang terlibat selama proyek berlangsung untuk dilakukan wawancara. Pekerja yang terlibat secara langsung dalam menangani proyek tersebut, akan lebih memahami kondisi yang terjadi selama proyek berlangsung hingga akhirnya terjadi keterlambatan. Penentuan pekerja sangat penting dalam wawancara ini, karena saat dilakukan wawancara narasumber melakukan penentuan nilai untuk setiap SOD. Pekerja yang akan diwawancara tersebut juga telah ditentukan sendiri oleh direktur dari PT X. Dimana pekerja yang telah ditentukan merupakan orang yang memahami serta mengkontrol proyek secara langsung, dan juga merupakan orang kepercayaan direktur selama proyek tersebut berlangsung. Dengan dua narasumber yang telah ditentukan oleh direktur, satu narasumber bagian kantor dan satu narasumber bagian lapangan akan membuat penentuan nilai SOD sesuai dengan kondisi yang terjadi pada saat proyek berlangsung. 


\subsection{Analisis Data}

Penulis melakukan memodifikasi deskripsi yang ada pada peneliti terdahulu dari deskripsi pengaruh risiko terhadap biaya, jadwal, dan kualitas menjadi dirangkum menjadi sebuah kegagalan. Untuk cidera diganti dengan adanya penambahan presentase keterlambatan untuk setiap item pekerjaan, karena selama PT X berdiri belum pernah terjadi kecelakaan kerja. Hal ini diucapkan oleh narasumber yang akan diwawancarai dan penulis memastikan kembali ke direktur PT X. Aspek keselamatan yang selalu diperhatikan dalam bekerja di PT X cukup baik, sehingga penulis mengganti kecelakaan saat bekerja dengan presetase keterlambatan yang sesuai dengan penelitian yang dilakukan. Deskripsi tabel severity dari Cheng and Lu (2015) yang dilakukan modifikasi oleh penulis untuk menyesuaikan kondisi yang ada menjadi Tabel 1 di bawah ini sebagai berikut.

Tabel 1 Tabel severity yang digunakan dalam penelitian

\begin{tabular}{|c|c|c|}
\hline Kategori & Skala & Deskripsi \\
\hline \multirow{2}{*}{$\begin{array}{l}\text { Sangat } \\
\text { Rendah }\end{array}$} & 1 & Kegagalan sangat kecil, yang menyebabkan keterlambatan (0-10 hari) \\
\hline & 2 & Kegagalan sangat kecil, yang menyebabkan keterlambatan (11-20 hari) \\
\hline \multirow{2}{*}{ Rendah } & 3 & $\begin{array}{l}\text { Kegagalan kecil, yang menyebabkan proyek sedikit tertunda sehingga menyebabkan keterlambatan (21-30 } \\
\text { hari) }\end{array}$ \\
\hline & 4 & $\begin{array}{l}\text { Kegagalan kecil, yang menyebabkan proyek sedikit tertunda sehingga menyebabkan keterlambatan (31-40 } \\
\text { hari) }\end{array}$ \\
\hline \multirow{2}{*}{ Menengah } & 5 & $\begin{array}{l}\text { Kegagalan menengah, yang menyebabkan proyek sedikit tertundah sehingga menyebabkan keterlambatan } \\
(41-50 \text { hari) }\end{array}$ \\
\hline & 6 & $\begin{array}{l}\text { Kegagalan menengah, yang menyebabkan proyek sedikit tertunda sehingga menyebabkan keterlambatan } \\
(51-60 \text { hari) }\end{array}$ \\
\hline \multirow[t]{2}{*}{ Tinggi } & 7 & $\begin{array}{l}\text { Kegagalan bahaya, yang menyebabkan proyek sedikit tertunda sehingga menyebabkan keterlambatan (61- } \\
70 \text { hari) }\end{array}$ \\
\hline & 8 & Kegagalan bahaya, yang menyebabkan proyek tertunda dan menyebabkan keterlambatan (71-80 hari) \\
\hline \multirow{2}{*}{$\begin{array}{l}\text { Sangat } \\
\text { Tinggi }\end{array}$} & 9 & $\begin{array}{l}\text { Kegagalan sangat bahaya, yang menyebabkan proyek hampir tidak beroperasi sehingga mengalami } \\
\text { keterlambatan ( } 81-90 \text { hari) }\end{array}$ \\
\hline & 10 & $\begin{array}{l}\text { Kegagalan sangat bahaya, yang menyebabkan proyek tidak beroperasi sehingga mengalami } \\
\text { keterlambatan ( } 91-100 \text { hari) }\end{array}$ \\
\hline
\end{tabular}

Tabel occurence yang digunakan ini menggunakan refrensi dari Liu, Kong, dan Zhang (2018), tabel ini digunakan untuk mengidentifikasi probabilitas masalah yang terjadi dalam penilaian yang akan dilakukan. Deskripsi yang ada dapat menyesuaikan kondisi probabilitas, sehingga tidak diperlukan modifikasi untuk menggunakan sebagai deskripsi penilaian occurence. Satu deskripsi yang memiliki dua skala ini cara menentukannya adalah, angka yang terkecil adalah yang paling sesuai dengan deskripsi. Angka yang lebih besar dari satu deskripsi tersebut merupakan faktor yang kurang sesuai dalam penilaian. Tabel 2 dapat dilihat di bawah ini sebagai berikut.

Tabel 2 Tabel occurence Liu, Kong, dan Zhang (2018) yang digunakan dalam penelitian

\begin{tabular}{ccl}
\hline Kategori & Skala & Deskripsi \\
\hline Minimal & $1-2$ & Peluang terjadinya faktor risiko sangat rendah, hampir tidak terjadi \\
\hline Minor & $3-4$ & Peluang terjadinya faktor risiko rendah, jarang terjadi \\
\hline Moderat & $5-6$ & Peluang terjadinya faktor risiko moderat, terjadi sesekali \\
\hline Mayor & $7-8$ & Peluang terjadinya faktor risiko tinggi, berulang \\
\hline Ekstrem & $9-10$ & Peluang terjadinya faktor risiko tinggi, sulit dihindari \\
\hline
\end{tabular}


Tabel detection ini menggunakan refrensi dari Villarini, Cesarotti, Alfonsi, and Introna (2017) untuk mengidentifikasi deteksi masalah yang terjadi dalam penilaian yang akan dilakukan. Deskripsi yang ada sudah jelas dan dapat menyesuaikan kondisi dalam mendeteksi permasalahan yang ada. Satu deskripsi yang memiliki dua skala ini cara menentukannya adalah, angka yang terbesar adalah yang paling sesuai dengan deskripsi. Angka yang lebih kecil dari satu deskripsi tersebut merupakan salah satu dari deskripsi tim proyek yang tidak dapat dilakukan dalam penilaian. Tabel 3 dapat dilihat di bawah ini sebagai berikut.

Tabel 3 Tabel detection Villarini, Cesarotti, Alfonsi, and Introna (2017) yang digunakan dalam penelitian

\begin{tabular}{ccc}
\hline Kategori & Skala & \multicolumn{1}{c}{ Deskripsi } \\
$\begin{array}{c}\text { Sangat } \\
\text { Rendah }\end{array}$ & $9-10$ & $\begin{array}{l}\text { Tim (proyek) hampir tidak bisa: mengidentifikasi risiko, mengendalikan akar penyebab, dan tidak dapat } \\
\text { mengelola konsekuensi risiko }\end{array}$ \\
\hline Rendah & $7-8$ & $\begin{array}{l}\text { Tim (proyek) dapat: mengidentifikasi respon risiko yang memiliki peluang rendah dalam memperhatikan } \\
\text { risiko, dapat mengendalikan akar penyebab, dan mengelola konsekuensi risiko }\end{array}$ \\
\hline Menengah & $5-6$ & $\begin{array}{l}\text { Tim (proyek) dapat: mengidentifikasi respon risiko yang memiliki peluang sedang dalam memperhatikan } \\
\text { risiko, dapat mengendalikan akar penyebab, dan mengelola konsekuensi risiko }\end{array}$ \\
\hline Tinggi & $3-4$ & $\begin{array}{l}\text { Tim (proyek) dapat: mengidentifikasi respon risiko yang memiliki peluang tinggi dalam memperhatikan } \\
\text { risiko, dapat mengendalikan akar penyebab, dan mengelola konsekuensi risiko }\end{array}$ \\
\hline $\begin{array}{c}\text { Sangat } \\
\text { Tinggi }\end{array}$ & $1-2$ & $\begin{array}{l}\text { Tim (proyek) dapat: mengidentifikasi respon risiko yang terbukti memiliki ke efektifan yang tinggi dalam } \\
\text { memperhatikan risiko, dapat mengendalikan akar penyebab, dan mengelola konsekuensi risiko }\end{array}$ \\
\hline
\end{tabular}

Kriteria tabel pedoman telah dijelaskan dengan deskripsi pada setiap tabel SOD di atas, nilainya akan ditentukan oleh narasumber dalam wawancara sesuai dengan kondisi yang ada. Hasil nilai SOD yang telah terisi untuk setiap item pekerjaan, akan diolah untuk mendapatkan nilai RPN pada setiap item pekerjaannya. Hasil nilai wawancara akan dibandingkan antara bagian kantor dan bagian lapangan, perbandingan nilai SOD untuk wawancara awal yang telah dilakukan sebesar dua angka untuk setiap item beserta nilainya. Tujuan dari pembatasan selisi nilai untuk mendapatkan item pekerjaan yang kritis sehingga perlu diprioritaskan dan diteliti lebih detail untuk mengetahui permasalahan yang terjadi. Selisih nilai yang lebih dari dua akan ditanyakan kembali dengan alasan-alasan yang dapat dilogika, sehingga tidak hanya memberikan nilai berdasarkan pendapat masing-masing pada bidang dan tanggung jawabnya.

\subsection{Proyek 1 (Luhu-Kambelo)}

Pada Tabel 4 menunjukan untuk proyek 1, angka RPN yang lebih dari 125 ada lima item. Item pekerjaan yang menjadi prioritas dalam penelitian ini ada faktor risiko I, E, D, B, dan J. Prioritas faktor risiko dapat dilihat pada Tabel 4 di bawah ini sebagai berikut.

Tabel 4 Lima prioritas faktor risiko dari proyek 1 yang diteliti

\begin{tabular}{|c|c|c|c|c|c|c|c|c|c|c|c|c|}
\hline \multirow[t]{2}{*}{ Item } & \multirow[t]{2}{*}{ Faktor Risiko } & \multicolumn{3}{|c|}{ Severity } & \multicolumn{3}{|c|}{ Ocurrence } & \multicolumn{3}{|c|}{ Detection } & \multirow[t]{2}{*}{ RPN (X) } & \multirow[t]{2}{*}{$\mathbf{P}$} \\
\hline & & $\mathbf{K}$ & $\mathbf{L}$ & Xs & $\mathbf{K}$ & $\mathbf{L}$ & Xo & $\mathbf{K}$ & $\mathbf{L}$ & Xd & & \\
\hline I & Struktur batu lebih keras & 6 & 6 & 6 & 7 & 8 & 7,5 & 7 & 8 & 7,5 & 337,5 & 1 \\
\hline $\mathbf{E}$ & Menunggu spare part & 6 & 6 & 6 & 5 & 6 & 5,5 & 6 & 7 & 6,5 & 214,5 & 2 \\
\hline D & Kerusakan pada exchavator & 7 & 8 & 7,5 & 4 & 4 & 4 & 7 & 7 & 7 & 210,0 & 3 \\
\hline B & Kondisi dump truck kurang prima & 5 & 6 & 5,5 & 4 & 5 & 4,5 & 7 & 8 & 7,5 & 185,6 & 4 \\
\hline $\mathbf{J}$ & Struktur tanah dengan campuran batu & 4 & 4 & 4 & 6 & 6 & 6 & 7 & 7 & 7 & 168,0 & 5 \\
\hline
\end{tabular}

Prioritas item pekerjaan yang telah didapatkan sebagai faktor keterlambatan saat proyek berlangsung akan di breakdown kembali. Hal ini bertujuan untuk mendapatkan penyebab utama dalam item pekerjaan tersebut hingga menimbulkan dampak keterlambatan. Pembahasan dalam wawancara awal yang telah dilakukan merupakan permaasalahan dan akibat dari masalah yang 
tesebut pada item pekerjaannya. Keterangan tersebut digunakan untuk mencari solusi yang berdampak untuk mengurangi keterlambatan. Pembahasan selama wawancara dirangkum dan disederhanakan seperti pada Tabel 5 di bawah ini sebagai berikut.

Tabel 5 Pemecahan masalah dan pengusulan solusi untuk proyek 1

\begin{tabular}{|c|c|c|c|c|}
\hline Item & Faktor Risiko & RPN & Dampak Risiko & Solusi \\
\hline \multirow{4}{*}{$\mathbf{I}$} & \multirow{4}{*}{$\begin{array}{l}\text { Struktur batu } \\
\text { lebih keras dari } \\
\text { data }\end{array}$} & \multirow{4}{*}{337,5} & \multirow{2}{*}{$\begin{array}{l}\text { Proses pekerjaan galian } \\
\text { atau cutting batu terlambat }\end{array}$} & $\begin{array}{l}\text { Meminta data kekerasan batu dari hasil uji laboratorium dari } \\
\text { konsultan }\end{array}$ \\
\hline & & & & Membawa alat test portable kekerasan batu \\
\hline & & & \multirow{2}{*}{$\begin{array}{l}\text { Satu unit exchavator } \\
\text { mengalami kerusakan }\end{array}$} & Menggunakan exchavator yang dapat diganti dengan breaker \\
\hline & & & & Memodifikasi bucket dengan penambahan plat \\
\hline \multirow{3}{*}{$\mathbf{E}$} & \multirow{3}{*}{$\begin{array}{l}\text { Menunggu } \\
\text { spare part dari } \\
\text { Kota Surabaya }\end{array}$} & \multirow{3}{*}{214,5} & \multirow{3}{*}{$\begin{array}{l}\text { Pekerjaan cutting gunung } \\
\text { dan galian selokan } \\
\text { terhambat }\end{array}$} & Memperbaiki sistem gudang \\
\hline & & & & Menyediakan stock spare part (yang sering diganti) \\
\hline & & & & Mempersiapkan alat drill/ bor tanah untuk galian selokan \\
\hline \multirow{3}{*}{ D } & \multirow{3}{*}{$\begin{array}{l}\text { Kerusakan } \\
\text { pada } \\
\text { exchavator }\end{array}$} & \multirow{3}{*}{210} & \multirow{3}{*}{$\begin{array}{l}\text { Satu unit exchavator tidak } \\
\text { dapat beroperasional } \\
\text { selama maintenance }\end{array}$} & Mempersiapkan dan menentukan alat yang dalam kondisi prima \\
\hline & & & & Melakukan preventive maintenance untuk alat berat \\
\hline & & & & Memodifikasi bucket dengan penambahan plat \\
\hline \multirow{3}{*}{ B } & \multirow{3}{*}{$\begin{array}{l}\text { Kondisi dump } \\
\text { truck kurang } \\
\text { prima }\end{array}$} & \multirow{3}{*}{185,6} & \multirow{3}{*}{$\begin{array}{l}\text { Volume material yang } \\
\text { diperlukan tidak dapat } \\
\text { terpenuhi }\end{array}$} & Menambah jumlah unit dump truck perusahaan/sewa \\
\hline & & & & Menerapkan preventive maintenance untuk dump truck \\
\hline & & & & Menugaskan sopir lincah dan mengerti kendaraan \\
\hline \multirow{2}{*}{$\mathbf{J}$} & \multirow{2}{*}{$\begin{array}{l}\text { Struktur tanah } \\
\text { dengan } \\
\text { campuran batu } \\
\text { keras }\end{array}$} & \multirow{2}{*}{168} & \multirow{2}{*}{$\begin{array}{l}\text { Proses pekerjaan galian } \\
\text { atau cutting tanah } \\
\text { terlambat }\end{array}$} & $\begin{array}{l}\text { Meminta data struktur tanah dari hasil uji laboratorium dari } \\
\text { konsultan }\end{array}$ \\
\hline & & & & Membawa alat test portable uji tanah \\
\hline
\end{tabular}

Wawancara ke dua dilakukan kembali untuk mendapatkan perbandingan nilai RPN setelah mendapatkan solusi untuk keterlambatan proyek. Nilai yang didapat tetap menggunakan panduan tabel yang telah ditentukan dapat dilihat pada Tabel 1 - Tabel 3 di atas. Konteks pembahasan dalam wawancara kedua ini merupakan prioritas item pekerjaan yang telah diketahui keterlambatannya disebabkan oleh faktor apa hingga berdampak pada keterlambatan proyek. Pengambilan nilai ini dipilih dengan melihat dari segi kemudahan dalam menggunakan solusi yang diusulkan dan dampak yang terjadi ketika solusi yang disulkan akan diterapkan saat proyek 1 berjalan. Hasil wawancara yang dilakukan dapat dilihat sebagai berikut pada Tabel 6 di bawah ini.

Tabel 6 Hasil rata-rata wawancara jika solusi diterapkan untuk proyek 1

\begin{tabular}{|c|c|c|c|c|c|c|c|c|c|c|c|}
\hline \multirow{2}{*}{ Item } & \multirow{2}{*}{ Faktor Risiko } & \multicolumn{3}{|c|}{ Severity } & \multicolumn{3}{|c|}{ Ocurrence } & \multicolumn{3}{|c|}{ Detection } & \multirow{2}{*}{$\begin{array}{c}\text { RPN } \\
\text { (X) }\end{array}$} \\
\hline & & $\mathbf{K}$ & $\mathbf{L}$ & Xs & $\mathbf{K}$ & $\mathbf{L}$ & Xo & $\mathbf{K}$ & $\mathbf{L}$ & $\mathbf{X d}$ & \\
\hline I & Struktur batu lebih keras & 4 & 4 & 4 & 5 & 4 & 4,5 & 5 & 4 & 4,5 & 81 \\
\hline$E$ & Menunggu spare part & 4 & 5 & 4,5 & 5,5 & 5,5 & 5,5 & 2 & 3 & 2,5 & 61,9 \\
\hline D & Kerusakan exchavator & 4 & 3 & 3,5 & 4 & 4 & 4 & 5 & 6 & 5,5 & 77 \\
\hline B & Kondisi dump truck kurang prima & 3 & 2 & 2,5 & 4,5 & 4,5 & 4,5 & 5 & 6 & 5,5 & 61,9 \\
\hline $\mathbf{J}$ & Struktur tanah dengan campuran batu & 4 & 4 & 4 & 6 & 6 & 6 & 4 & 3 & 3,5 & 84 \\
\hline
\end{tabular}

Perbandingan nilai dalam proyek 1 ini sudah munurun cukup jauh dan sudah dibawah nilai minimum 125. Pengusulan solusi yang diberikan untuk proyek 1 ini membuat RPN disetiap faktor risiko menurun. Hasil perbandingan untuk proyek 1 dapat dilihat pada Tabel 7 di bawah ini sebagai berikut. 
Tabel 7 Hasil perbandingan nilai RPN proyek 1

\begin{tabular}{clccc}
\hline \multirow{2}{*}{ Item } & \multicolumn{1}{c}{ Faktor Risiko } & \multicolumn{3}{c}{ RPN } \\
\cline { 3 - 5 } & & Before & After & Penurunan \\
\hline I & Struktur batu lebih keras & 337,5 & 81 & 256,5 \\
\hline E & Menunggu spare part & 214,5 & 61,9 & 152,6 \\
\hline D & Kerusakan exchavator & 210,0 & 77 & 133,0 \\
\hline B & Kondisi dump truck kurang prima & 185,6 & 61,9 & 123,8 \\
\hline J & Struktur tanah dengan campuran batu & 168,0 & 84 & 84,0 \\
\hline
\end{tabular}

Dari hasil data Tabel 7 di atas dapat disimpulkan penurunan nilai RPN after yang lebih rendah dari RPN before dapat terjadi karena penentuan dari solusi yang digunakan untuk item pekerjaan tersebut. Pemberian solusi yang tepat dan berdampak untuk mengurangi atau meminimalkan keterlambatan proyek yang ada.

\subsection{Proyek 2 (Kambelo - Eli)}

Pada Tabel 8 menunjukan untuk proyek 2, angka RPN yang lebih dari 125 ada empat item. Item pekerjaan yang menjadi prioritas dalam penelitian ini ada faktor risiko $D, P, B$, dan $L$. Prioritas faktor risiko dapat dilihat pada Tabel 8 di bawah ini sebagi berikut.

Tabel 8 Empat prioritas faktor risiko proyek 2 yang diteliti

\begin{tabular}{|c|c|c|c|c|c|c|c|c|c|c|c|c|}
\hline \multirow[b]{2}{*}{ Item } & \multirow{2}{*}{ Faktor Risiko } & \multicolumn{3}{|c|}{ Severity } & \multicolumn{3}{|c|}{ Ocurrence } & \multicolumn{3}{|c|}{ Detection } & \multirow{2}{*}{$\begin{array}{c}\text { RPN } \\
\text { (X) }\end{array}$} & \multirow{2}{*}{$\mathbf{P}$} \\
\hline & & $\mathbf{K}$ & $\mathbf{L}$ & Xs & $\mathbf{K}$ & $\mathbf{L}$ & Xo & K & $\mathbf{L}$ & $\mathbf{X d}$ & & \\
\hline D & Curah hujan tinggi & 4 & 4 & 4 & 7 & 6 & 6,5 & 6 & 8 & 7 & 182,0 & 1 \\
\hline $\mathbf{P}$ & Volume timbunan dari su & 4 & 6 & 5 & 6 & 8 & 7 & 5 & 5 & 5 & 175,0 & 2 \\
\hline B & Kondisi dump truck kuran & 4 & 5 & 4,5 & 5 & 5 & 5 & 7 & 8 & 7,5 & 168,8 & 3 \\
\hline $\mathbf{L}$ & Mengangkut material dengan tenaga SDM & 4 & 5 & 4,5 & 7 & 6 & 6,5 & 5 & 6 & 5,5 & 160,9 & 4 \\
\hline
\end{tabular}

Prioritas item pekerjaan yang telah didapatkan sebagai faktor keterlambatan saat proyek berlangsung akan di breakdown kembali. Hal ini bertujuan untuk mendapatkan penyebab utama dalam item pekerjaan tersebut hingga menimbulkan dampak keterlambatan. Pembahasan dalam wawancara awal yang telah dilakukan merupakan permaasalahan dan akibat dari masalah yang tesebut pada item pekerjaannya. Keterangan tersebut digunakan untuk mencari solusi yang berdampak untuk mengurangi keterlambatan. Pembahasan selama wawancara dirangkum dan disederhanakan seperti pada Tabel 9 di bawah ini sebagai berikut.

Tabel 9 Pemecahan masalah dan pengusulan solusi untuk proyek 2

\begin{tabular}{|c|c|c|c|c|}
\hline Item & Faktor Risiko & RPN & Dampak Risiko & Solusi \\
\hline \multirow{3}{*}{ D } & \multirow{3}{*}{$\begin{array}{l}\text { Curah hujan } \\
\text { tinggi }\end{array}$} & \multirow{3}{*}{182} & \multirow{3}{*}{$\begin{array}{l}\text { Semua aktivitas tidak } \\
\text { dapat diselesaikan } \\
\text { sesuai jadwal yang } \\
\text { telah direncanakan }\end{array}$} & Melakukan sistem lembur disaat tidak hujan \\
\hline & & & & $\begin{array}{l}\text { Melengkapi kebutuhan proyek di Camp Luhu agar dapat di } \\
\text { mobilasikan saat cuaca membaik }\end{array}$ \\
\hline & & & & Membuat terop sederhana saat melakukan lapis resap pengikat \\
\hline \multirow{3}{*}{$\mathbf{P}$} & \multirow{3}{*}{$\begin{array}{l}\text { Volume } \\
\text { timbunan dari } \\
\text { sumber galian } \\
\text { tidak sesuai }\end{array}$} & \multirow{3}{*}{175} & \multirow{3}{*}{$\begin{array}{l}\text { Pekerjaan struktur } \\
\text { dasar menjadi terlambat }\end{array}$} & $\begin{array}{l}\text { Mengkomunikasikan dengan kepala dusun untuk memenuhi } \\
\text { kebutuhan proyek dengan kubikasi yang lebih baik sesuai } \\
\text { perjanjian di awal }\end{array}$ \\
\hline & & & & $\begin{array}{l}\text { Bernegosiasi dengan kepala dusun untuk mengambil material dari } \\
\text { tempat lain }\end{array}$ \\
\hline & & & & $\begin{array}{l}\text { Melakukan pengambilan dengan alat berat dari sumber galian } \\
\text { material terdekat }\end{array}$ \\
\hline
\end{tabular}


Tabel 10 Pemecahan masalah dan pengusulan solusi untuk proyek 2(lanjutan)

\begin{tabular}{|c|c|c|c|c|}
\hline Item & Faktor Risiko & RPN & Dampak Risiko & Solusi \\
\hline \multirow{3}{*}{ B } & \multirow{3}{*}{$\begin{array}{l}\text { Kondisi dump } \\
\text { truck kurang } \\
\text { prima }\end{array}$} & \multirow{3}{*}{168,8} & \multirow{3}{*}{$\begin{array}{l}\text { Volume material yang } \\
\text { diperlukan tidak dapat } \\
\text { terpenuhi }\end{array}$} & Menambah jumlah unit dump truck perusahaan/sewa \\
\hline & & & & Melakukan preventive maintenance untuk dump truck \\
\hline & & & & Menugaskan sopir yang lincah dan mengerti kendaraan \\
\hline \multirow{2}{*}{$\mathbf{L}$} & \multirow{2}{*}{$\begin{array}{l}\text { Mengangkut } \\
\text { material dengan } \\
\text { tenaga SDM }\end{array}$} & \multirow{2}{*}{160,9} & \multirow{2}{*}{$\begin{array}{l}\text { Perhitungan volume } \\
\text { dari perhitungan ret } \\
\text { yang direncanakan } \\
\text { tidak sesuai }\end{array}$} & $\begin{array}{l}\text { Mengkomunkasikan dengan kepala dusun untuk menambah } \\
\text { pekerjanya }\end{array}$ \\
\hline & & & & $\begin{array}{l}\text { Melakukan pengambilan dengan alat berat dari sumber galian } \\
\text { material terdekat }\end{array}$ \\
\hline
\end{tabular}

Wawancara ke dua dilakukan kembali untuk mendapatkan perbandingan nilai RPN setelah mendapatkan solusi untuk keterlambatan proyek. Nilai yang didapat tetap menggunakan panduan tabel SOD yang telah ditentukan dapat dilihat di Tabel 4.2 - Tabel 4.4 di atas. Konteks pembahasan dalam wawancara kedua ini merupakan prioritas item pekerjaan yang telah diketahui keterlambatannya disebabkan oleh faktor apa hingga berdampak pada keterlambatan proyek. Pengambilan nilai ini dipilih dengan melihat dari segi kemudahan dalam menggunakan solusi yang diusulkan dan dampak yang terjadi ketika solusi yang disulkan akan diterapkan saat proyek 2 berjalan. Hasil wawancara yang dilakukan dapat dilihat sebagai berikut pada Tabel 10 di bawah ini.

Tabel 11 Hasil rata-rata wawancara jika solusi diterapkan untuk proyek 2

\begin{tabular}{|c|c|c|c|c|c|c|c|c|c|c|c|}
\hline \multirow{2}{*}{ Item } & \multirow{2}{*}{ Faktor Risiko } & \multicolumn{3}{|c|}{ Severity } & \multicolumn{3}{|c|}{ Ocurrence } & \multicolumn{3}{|c|}{ Detection } & \multirow{2}{*}{$\begin{array}{c}\text { RPN } \\
(\mathbf{X})\end{array}$} \\
\hline & & $\mathbf{K}$ & $\mathbf{L}$ & Xs & $\mathbf{K}$ & L & Xo & $\mathbf{K}$ & L & Xd & \\
\hline D & Curah hujan tinggi & 2 & 3 & 2,5 & 6,5 & 6,5 & 6,5 & 3 & 2 & 2,5 & 40,6 \\
\hline $\mathbf{P}$ & $\begin{array}{l}\text { Volume timbunan dari sumber galian } \\
\text { tidak sesuai }\end{array}$ & 3 & 2 & 2,5 & 4 & 5 & 4,5 & 5 & 5 & 5 & 56,3 \\
\hline $\mathbf{B}$ & Kondisi dump truck kurang prima & 2 & 3 & 2,5 & 5 & 5 & 5 & 4 & 5 & 4,5 & 56,3 \\
\hline $\mathbf{L}$ & $\begin{array}{l}\text { Mengangkut material dengan tenaga } \\
\text { SDM }\end{array}$ & 3 & 2 & 2,5 & 6,5 & 6,5 & 6,5 & 4 & 4 & 4 & 65 \\
\hline
\end{tabular}

Perbandingan nilai dalam proyek 2 ini sudah munurun cukup jauh dan sudah dibawah nilai minimum 125. Pengusulan solusi yang diberikan untuk proyek 2 ini membuat penurunan setiap faktor risiko secara keseluruhan. Hasil perbandingan untuk proyek 2 dapat dilihat pada Tabel 11 sebagai berikut.

Tabel 12 Hasil Perbandingan Nilai RPN Proyek 2

\begin{tabular}{|c|c|c|c|c|}
\hline \multirow{2}{*}{ Item } & \multirow{2}{*}{ Faktor Risiko } & \multicolumn{3}{|c|}{ RPN } \\
\hline & & Before & After & Penurunan \\
\hline D & Curah hujan tinggi & 182,0 & 40,6 & 141,4 \\
\hline $\mathbf{P}$ & Volume timbunan dari sumber galian tidak sesuai & 175,0 & 56,3 & 118,8 \\
\hline B & Kondisi dump truck kurang prima & 168,8 & 56,3 & 112,5 \\
\hline $\mathbf{L}$ & Mengangkut material dengan tenaga SDM & 160,9 & 65 & 95,9 \\
\hline
\end{tabular}

Dari hasil data Tabel 11 di atas dapat disimpulkan penurunan nilai RPN after yang lebih rendah dari RPN before dapat terjadi karena penentuan dari solusi yang digunakan untuk item pekerjaan tersebut. Pemberian solusi yang tepat dan berdampak untuk mengurangi atau meminimalkan keterlambatan proyek yang ada. 


\subsection{Pembahasan}

Setelah melakukan wawancara dua kali untuk mengetahui nilai RPN before dan after untuk setiap proyek dapat diketahui perbandingannya. Perbandingan ini dilakukan agar mengetahui seberapa efektifnya FMEA dengan menggunakan 5 whys untuk mempermudah dalam memperbaiki serta mengurangi masalah keterlambatan yang terjadi. Perubahan nilai sangat berpengaruh dari solusi yang diberikan, di mana solusi diberikan harus dapat diimplementasikan dan efektif dalam menangani masalah yang ada. Solusi yang diberikan harus sesuai juga dengan situasi yang ada, agar nilai RPN after menurun dari nilai RPN beforenya. Hasil perbandingan RPN yang semakin jauh dapat diartikan sebagai keberhasilan dalam memberikan solusi yang diberikan.

\section{KESIMPULAN}

Berdasarkan item pekerjaan prioritas yang telah diteliti, pencarian akar permasalahan yang ada sudah mendapatkan solusi yang tepat. Pemberian solusi terhadap akar permasalahan tersebut, membuat nilai RPN after menjadi lebih rendah dari RPN before. Alasan dilakukan pemberian solusi agar penilaian angka SOD dapat menurun sesuai permasalah yang ada. Hal ini menunjukan pentingnya dilakukan pencarian akar permsalahan dalam keterlambatan proyek, dengan menggunakan metode FMEA dan 5 whys. Dengan adanya pemberian angka skala sebagai indikasi permasalahan, dan pencarian permasalahan yang dilakukan satu persatu membuat akar permasalahan dapat ditemukan.

Dari dua proyek yang telah diteliti ada sedikit kemiripan dalam akar permasalahan, namun tidak sama persis antara proyek 1 dan proyek 2 . Hal ini karena permasalahan yang terjadi berbeda tempat, situasi proyek, tim proyek yang dibentuk, dan faktor lainnya. Penilaian hasil wawancara yang telah dilakukan pada setiap bagian, dilakukan rata-rata karena untuk mendapatkan inti item pekerjaannya. Nilai pada hasil setiap wawancara berbeda karena setiap bagian memegang peranannya sendiri, sehingga untuk mendapatkan item pekerjaan dari hasil nilai yang lebih valid akan dilakukan rata-rata hasil SOD.

\section{DAFTAR PUSTAKA}

A Guide to the Project Management Body of Knowledge (PMBOK® guide). (5th ed.) Newtown Square, Pennsylvania: Project Management Institute, Inc., 2013. Retrieved from https://dinus.ac.id/repository/docs/ajar/PMBOKGuide_5th_Ed.pdf

Bahrami, M., Bazzaz, D. H., \& Sajjadi, S. M. (2012). Innovation and Improvements in Project Implementation and Management: Using FMEA Technique. Procedia - Social and Behavioral Sciences, 41, 418-425. https://doi.org/10.1016/j.sbspro.2012.04.050.

Cheng, M., \& Lu, Y. (2015). Developing a Risk Assessment Method for Complex Pipe Jacking Construction Projects. Automation in Construction, 58, 48-59. https://doi.org/10.1016/j.autcon.2015.07.011

Ebrahemzadih, M., H. Halvani, G., Shahmoradi, B., \& Giahi, O. (2014). Assessment and Risk Management of Potential Hazards by Failure Modes and Effect Analysis (FMEA) Method in Yazd Steel Complex. Open Journal of Safety Science and Technology, 04(03), 127-135. https://doi.org/10.4236/ojsst.2014.43014 
Labombang, M. (2012). Manajemen Risiko dalam Proyek Konstruksi. Jurnal SMARTek, 9(1), 3946. Retrieved from http://jurnal.untad.ac.id/jurnal/index.php/SMARTEK/article/view/618

Latief, Y. \& Utami, R.P.. (2009). Penerapan Pendekatan Metode Six Sigma dalam Penjagaan Kualitas pada Proyek Konstruksi. Makara Journal of Technology, 13(2), 67-72. https://doi.org/10.7454/mst.v13i2.471.

Liu, Y., Kong, Z., \& Zhang, Q. (2018). Failure Modes and Effects Analysis (FMEA) for the Security of the Supply Chain System of The Gas Station in China. Ecotoxicology And Environmental Safety, 164, 325-330. https://doi.org/10.1016/j.ecoenv.2018.08.028

Tafazzoli, M. (2017). Dynamic Risk Analysis of Construction Delays Using Fuzzy-Failure Mode Effects Analysis. UNLV Theses, Dissertations, Professional Papers, and Capstones. 3043. https://digitalscholarship.unlv.edu/thesesdissertations/3043

Villarini, M., Cesarotti, V., Alfonsi, L., \& Introna, V. (2017). Optimization of Photovoltaic Maintenance Plan by Means of A FMEA Approach Based on Real Data. Energy Conversion and Management, 152, 1-12. https://doi.org/10.1016/j.enconman.2017.08.090

Wachyudi, Yusuf (2010). Identifikasi Bahaya, Analisis, dan Pengandalian Risiko dalam Tahap Desain Proses Produksi Minyak \& Gas di Kapal Floating Production Storage \& Offloading (FPSO) untuk Projek Petronas Bukit Tua Tahun 2010. (S2), Universitas Indonesia, Depok. (0806442626)

Wehbe, F. A., \& Hamzeh, F. R. (2013). Failure Mode and Effect Analysis as a Tool for Risk Management in Construction Planning. In C. T. Formoso \& P. Tzortzopoulos (Eds.), 21th Annual Conference of the International Group for Lean Construction (pp. 481-490). Retrieved from http://iglc.net/Papers/Details/961/pdf 